\title{
Hemoglobin adducts in workers exposed to 1,6-hexamethylene diisocyanate
}

\author{
Sheila L. Flack ${ }^{1}$, Kenneth W. Fent ${ }^{1}$, Linda G. T. Gaines ${ }^{1}$, Jennifer M. Thomasen ${ }^{1}$, Stephen \\ G. Whittaker ${ }^{2}$, Louise M. Ball ${ }^{1}$, and Leena A. Nylander-French ${ }^{1}$ \\ ${ }^{1}$ Department of Environmental Sciences and Engineering, Gillings School of Global Public Health, \\ The University of North Carolina at Chapel Hill, NC, USA \\ ${ }^{2}$ Local Hazardous Waste Management Program, Public Health-Seattle \& King County, Seattle, \\ Washington, USA
}

\section{Abstract}

We investigated the utility of 1,6-hexamethylene diamine (HDA) hemoglobin adducts as biomarkers of exposure to 1,6-hexamethylene diisocyanate (HDI) monomer. Blood samples from 15 spray painters applying HDI-containing paint were analyzed for hemoglobin HDA (HDA-Hb) and $N$-acetyl-1,6-hexamethylene diamine (monoacetyl-HDA-Hb) by GC-MS. HDA-Hb was detected in the majority of workers ( $₫ .2-37 \mathrm{ng} / \mathrm{g} \mathrm{Hb}$ ), whereas monoacetyl-HDA-Hb was detected in one worker $(0.06 \mathrm{ng} / \mathrm{g} \mathrm{Hb})$. The stronger, positive association between HDA-Hb and cumulative HDI exposure $\left(r^{2}=0.3, p<0.06\right)$ than same day exposure $(p \geq 0.13)$ indicates longterm elimination kinetics for HDA-Hb adducts. This association demonstrates the suitability of $\mathrm{HDA}-\mathrm{Hb}$ adducts for further validation as a biomarker of HDI exposure.

\section{Keywords}

1,6-hexamethylene diamine (HDA); hemoglobin; adduct; biomarker; 1,6-hexamethylene diisocyanate (HDI)

\section{Introduction}

1, 6-Hexamethylene diamine (HDA) in biological media (e.g., urine, plasma) has been utilized as a biological marker for occupational exposure to 1,6-hexamethylene diisocyanate (HDI) (Maître et al. 1996, Williams et al. 1999, Rosenberg et al. 2002, Pronk et al. 2006, Flack et al. 2010a). During automotive spray painting, workers may be exposed to HDI present in paint formulations via skin or inhalation routes. In biological samples, these markers represent the integration of HDI exposure across multiple exposure routes. Repeated or prolonged exposure to HDI monomer and/or HDI oligomers (e.g., uretdione, biuret, and isocyanurate) may also result in skin or respiratory sensitization (Zissu et al.

\section{(C) 2011 Informa UK, Ltd.}

Address for Correspondence: Leena A. Nylander-French, Department of Environmental Sciences and Engineering, Gillings School of Global Public Health, The University of North Carolina at Chapel Hill, CB \#7431, Rosenau Hall, Chapel Hill, NC 27599-7431, USA. Tel.: (919) 966-3826, Fax: (919) 966-7911. leena_french@unc.edu. 
1998, Pronk et al. 2007, Aalto-Korte et al. 2010) and development of occupational asthma (Cockcroft \& Mink, 1979, Vandenplas et al. 1993). Trace amounts of HDI monomer and larger amounts of HDI oligomer as vapors and/or aerosols are produced during painting with isocyanate-containing paints (Janko et al. 1992, Lesage et al. 1992, Sparer et al. 2004, Pronk et al. 2006). Repeated skin exposure at these trace levels to HDI monomer $(0.1 \%)$ may cause skin sensitization, which can develop to asthma following inhalation exposure to HDI monomer (Herrick et al. 2002). Therefore, characterizing and quantifying biomarkers of HDI monomer exposure continues to be critical in evaluating workplace exposure, developing strategies for mitigating exposure, and preventing adverse health effects.

HDA in acid-hydrolyzed urine and plasma are the only validated biomarkers to date for short-term (Tinnerberg et al. 1995, Maître et al. 1996, Gaines et al. 2010) and cumulative exposure to HDI monomer (Flack et al. 2010a). Once in the body, the isocyanato moiety (NCO) may be hydrolyzed to an amine (e.g., HDA), catalyzed by bicarbonate in the blood (Berode et al. 1991), or may react with proteins, such as albumin and hemoglobin (Hb), to form protein adducts. HDA could be $\mathrm{N}$-acetylated by $\mathrm{N}$-acetyltransferase (NAT) to form $\mathrm{N}$ acetyl-1,6-hexamethylene diamine (monoacetyl-HDA) (Brorson et al. 1990a) and $N, N^{\prime}-$ diacetyl-1,6-hexamethylene diamine (diacetyl-HDA), which is rapidly excreted. The amine group may also undergo $\mathrm{N}$-oxidation by cytochrome $\mathrm{P} 450$ or a flavin adenine dinucleotidedependent enzyme system, such as flavin-containing monooxygenase (FMO), and be further oxidized to form reactive intermediates, such as nitroso derivatives (Gorrod, 1973, Beedham, 1997). The oxidation pathway would eventually result in the formation of isocyanate-derived protein adducts, with the potential to persist over the half-life of albumin $\left(t_{1 / 2}=19\right.$ days) (Peters, 1975) or the lifespan of $\mathrm{Hb}$ (120 days) (Landaw, 1991). Individual differences in acetylator genotype (fast vs. slow) that drive these dominant enzymaticdirected pathways have been linked with asthma risk (Wikman et al. 2002). The nonenzymatic formation of protein adducts may occur via hydrolysis of bis-dithiocarbamate intermediates resulting from the reaction of $\mathrm{NCO}$ with thiols, such as cysteine (Chipinda et al. 2006). In a human case study, HDI protein adducts were detected in lung tissue following exposure to HDI, demonstrating that blood proteins are suitable markers for exposure and target-dose estimation (Redlich et al. 1997). Different protein adducts or metabolites formed from these various non-enzymatic or enzymatic-directed pathways following HDI monomer exposure have not been fully characterized in exposed individuals. Such information would help to identify important metabolic intermediates that are indicators of individual susceptibility for asthma and other health effects.

The main advantage in measuring blood biomarkers of HDI exposure is to obtain internal dose measures of cumulative exposures due to the formation of long-lived protein adducts. The stronger correlation between HDA in acid-hydrolyzed plasma and dermal or inhalation exposure to HDI monomer occurring $~ 0.5-2$ months before blood collection compared with the same day exposure among 46 spray painters demonstrated the presence of longer-lived albumin adducts (Flack et al. 2010a). Moreover, a biphasic elimination pattern has been described for diisocyanate-derived amines, thought to result from the rapid urinary excretion of short-term metabolites within a few hours (Brorson et al. 1990b, Tinnerberg et al. 1995), followed by the excretion of long-lived protein adducts days later (Lind et al. 1997). The 
presence of HDA in the majority of first-day, pre-exposure urine samples among HDIexposed spray painters, also indicated the slow elimination of protein conjugates accumulated during the work week (Gaines et al. 2010). In addition to being an indicator of past exposure to diisocyanates, protein adducts may contribute to the pathogenesis of diisocyanate-induced asthma by their action as protein carriers in presenting HDI to the immune system (Wisnewski et al. 2000). Therefore, the correlation between HDI exposure levels and HDA-protein adducts in blood would provide additional information on the uptake and elimination kinetics of HDI metabolites and, thus, the biological availability of these reaction products in contributing to disease development.

The presence of $\mathrm{Hb}$ adducts may indicate cumulative exposure across a more extensive period of time ( $\ 20$ days) compared with albumin adducts (19-day half-life) or free HDA (several hours). A benefit of $\mathrm{Hb}$ adduct analysis is the enhanced specificity compared with HDA analysis using acid-hydrolysis. Measured HDA from acid-hydrolyzed plasma (i.e., plasma HDA) or urine (i.e., urine HDA) may be derived from both unbound and proteinconjugated HDA (e.g., albumin-HDA) and monoacetyl-HDA, as well as unbound diacetylHDA. Acid treatment of plasma or urine masks individual variability in the types and yield of various metabolites which, in turn, could provide information about susceptibility factors and mechanisms related to disease development. $\mathrm{Hb}$ isolation followed by mild base treatment has resulted in the identification of 4, 4'-methylene dianiline (MDA) and monoacetyl-MDA adducts (Sepai et al. 1995), and these methods could be applied to blood samples for identifying HDA-Hb and monoacetyl-HDA-Hb adducts.

The mechanism by which reactive diisocyanates are transported across the epithelial layer of the respiratory tract, into the blood, and through the erythrocyte membrane to react with $\mathrm{Hb}$ is unknown, but may involve the formation of mono- and bis-thiocarbamate intermediates (Chipinda et al. 2006). Such products formed by the reaction of diisocyanate with cysteine would allow transport across cellular membranes. It has been postulated that the bisthiocarbamate product could be carried from the lung to a distal site, whereupon hydrolysis would occur, releasing a free diisocyanate that could react with another nucleophile (Chipinda et al. 2006). Because the rates of hydrolysis among the different diisocyanate intermediates vary widely, the biological availability of reactive intermediates may also vary. Thus, investigation of HDA-Hb adducts would provide important information on potential metabolic pathways and reaction products related to diisocyanate-mediated hypersensitivity diseases.

There are no publications reporting the proportion of $\mathrm{Hb}$ to albumin adducts resulting from HDI exposure and how these protein adduct levels vary with urine HDA levels. Sepai et al (1995) reported MDA-Hb adduct levels in all 20 exposed workers to 4,4'-methylene diphenyl diisocyanate (MDI), and monoacetyl-MDA was detected as $\mathrm{Hb}$ adducts in one worker. However, the albumin adduct levels in plasma were 450-fold higher than the $\mathrm{Hb}$ adduct levels. Whether albumin adducts are also the dominant products formed from HDI exposure has yet to be investigated. Additionally, different levels of $\mathrm{Hb}$ adducts and urinary MDA corresponding to MDI or MDA exposure and varying MDA-Hb levels by exposure route (i.e., dermal or inhalation) have been observed (Pauluhn \& Lewalter, 2002). In our previous study, plasma HDA levels were modified by coverall use and type of ventilated 
paint booth that the workers used during spray painting (Flack et al. 2010a). Therefore, exposure route, stability of metabolic intermediates, and exposure to the diisocyanate versus the diamine (e.g., HDI vs. HDA) may drive specific metabolic pathways of HDI and, consequently, the types and yields of products formed.

The objectives of this study were to: (i) quantify $\mathrm{Hb}$ adducts of HDA and monoacetyl-HDA resulting from HDI exposure, using mild base treatment, in 15 exposed spray painters, and (ii) investigate these measures as biomarkers of short- or long-term HDI exposure by correlating levels of HDA in acid-treated plasma or $\mathrm{Hb}$ adducts with same day or cumulative HDI monomer air, dermal, or inhalation exposure levels.

\section{Materials and methods}

\section{Chemicals}

Solvents and chemicals were purchased from Thermo Fisher (Hampton, NH): HPLC grade (99.9\%) dichloromethane (\#AC61005-0040), ethyl acetate (\#AC61006- 0040), acetonitrile (\#AC61001-0040), sodium sulfate anhydrous (certified ACS, \#S421-500), acetic anhydride (>99\%, \#AC14949-0010), sodium hydroxide (certified ACS, \#S318-500), and $\mathrm{Hb}$ (\#ICN10071425); and from Sigma-Aldrich (St. Louis, MO): HDA ( $₫ 99 \%$, \#33000), 1,7diaminoheptane (98\%, \#D17408), and heptafluorobutyric anhydride (derivatization grade, \#394912).

\section{Preparation of HDA and acetylated HDA (standard) mixture}

A standard mixture of HDA, monoacetyl-HDA, and diacetyl-HDA was prepared by making a $2 \mathrm{mg} / \mathrm{ml}$ solution of HDA in ethyl acetate ( $50 \mathrm{ml}$ total volume). Acetic anhydride was added dropwise at 0.9:1 molar ratio (acetic anhydride to HDA) with constant stirring at room temperature. The solution was allowed to react for $2 \mathrm{~h}$ and was subsequently filtered under vacuum using a $0.22 \mu \mathrm{m}, 25 \mathrm{~mm}$ nylon filter. A portion of the filtrate was dried under nitrogen and a $1 \mathrm{mg} / \mathrm{ml}$ solution of the dried product prepared in ethyl acetate. In order to quantify the amount of diacetyl-HDA in the standard mixture, a solution of diacetyl-HDA ( $299 \%$ ) was synthesized by preparing a $2 \mathrm{mg} / \mathrm{ml}$ solution of HDA in ethyl acetate $(50 \mathrm{ml}$ total volume) and adding acetic anhydride dropwise at 4:1 molar ratio (acetic anhydride to HDA) with constant stirring at room temperature. The solution was allowed to react for $2 \mathrm{~h}$ and was subsequently filtered under vacuum using a $0.22 \mu \mathrm{m}, 25 \mathrm{~mm}$ nylon filter. A portion of the filtrate was dried under nitrogen and a $1 \mathrm{mg} / \mathrm{ml}$ solution of the dried product prepared in ethyl acetate. Gas chromatography-mass spectrometry (GC-MS) analysis of the diacetylHDA mixture showed the product to be $\geq 99 \%$ pure (Flack et al. 2010b).

\section{Preparation of HpDA and acetylated HpDA (internal standard) mixture}

An internal standard (IS) mixture of 1,7-diaminoheptane (HpDA), monoacetyl-HpDA, and diacetyl-HpDA was prepared by making a $2 \mathrm{mg} / \mathrm{ml}$ solution of HpDA in ethyl acetate $(50 \mathrm{ml}$ total volume). Acetic anhydride was added dropwise at 0.9:1 molar ratio (acetic anhydride to HpDA) with constant stirring at room temperature. The solution was allowed to react for $2 \mathrm{~h}$ and was subsequently filtered under vacuum using a $0.22 \mu \mathrm{m}, 25 \mathrm{~mm}$ nylon filter. A portion 
of the filtrate was dried under nitrogen and a $1 \mathrm{mg} / \mathrm{ml}$ solution of the dried product prepared in ethyl acetate, and stored at $4^{\circ} \mathrm{C}$.

\section{Preparation of HDA and diacetyl-HDA standard curves}

To quantify HDA, monoacetyl-HDA, and diacetyl-HDA in the standard mixture, calibration standards of HDA and diacetyl-HDA were prepared in ethyl acetate. First, HDA and IS solutions $(1 \mu \mathrm{g} / \mathrm{ml})$ were prepared. A $5 \mu \mathrm{g} / \mathrm{ml}$ solution of diacetyl-HDA was prepared in ethyl acetate. A 1:1 serial dilution (1 ml total volume) of HDA and diacetyl-HDA solutions (in duplicate) was performed in ethyl acetate to obtain a concentration range: HDA (0-1 $\mu \mathrm{g} /$ $\mathrm{ml})$ and diacetyl-HDA $(0-5 \mu \mathrm{g} / \mathrm{ml})$. Each diluted sample of HDA or diacetyl-HDA was spiked with $100 \mu \mathrm{l}$ of $1 \mu \mathrm{g} / \mathrm{ml}$ IS mixture (final concentration $=0.1 \mu \mathrm{g} / \mathrm{ml}$ ). Diluted standard mixture solutions $(5 \mu \mathrm{g} / \mathrm{ml})$ were prepared in ethyl acetate $(1 \mathrm{ml}$ total volume) and spiked with $100 \mu \mathrm{l}$ of $1 \mu \mathrm{g} / \mathrm{ml}$ IS mixture. Solutions were reacted with $10 \mu \mathrm{l}$ heptafluorobutyric acid (HFBA) for $1 \mathrm{~h}$ at $55^{\circ} \mathrm{C}$ and immediately analyzed by GC-MS.

\section{GC-MS analysis}

Samples were analyzed by GC-MS (Thermo Trace GC Ultra interfaced with a PolarisQ ion trap mass spectrometer and AI/AS 3000 injector, and Xcalibur 1.4 SR1 software; Thermo Electron Corporation, Austin, TX). Injections ( $1 \mu \mathrm{l})$ were made under splitless mode of $30 \mathrm{~s}$ with injector temperature of $220^{\circ} \mathrm{C}$. Separation of the samples was carried out with a GC capillary column (DB5-MS, $30 \mathrm{~m} \times 0.25 \mathrm{~mm}$ ID, $0.1 \mu \mathrm{m}$ film thickness; Agilent Technologies, Palo Alto, CA). The ion source and GC transfer line temperatures were maintained at 150 and $260^{\circ} \mathrm{C}$, respectively. Helium was used as the carrier gas with a constant flow of $1 \mathrm{ml} / \mathrm{min}$. The GC oven temperature program was $50^{\circ} \mathrm{C}(1.0 \mathrm{~min})$ to $155^{\circ} \mathrm{C}$ at $10^{\circ} \mathrm{C} / \mathrm{min}, 155-185^{\circ} \mathrm{C}$ at $2^{\circ} \mathrm{C} / \mathrm{min}$, and $185-300^{\circ} \mathrm{C}$ at $25^{\circ} \mathrm{C} / \mathrm{min}$ (final temperature held for $10 \mathrm{~min}$ ). Ions were monitored in negative ion chemical ionization mode using methane as the reagent gas $(1.8 \mathrm{ml} / \mathrm{min})$. Mass spectra were acquired in the mass-to-charge ratio $(\mathrm{m} / \mathrm{z}$ ) range $200-600$.

GC-MS analysis of the standard curves and standard mixture revealed that the major ions corresponding to derivatized HDA, monoacetyl-HDA, and diacetyl-HDA were $m / z 448$ [M$60]^{-}$eluting at $14.1 \mathrm{~min}, 510$ [M-40]-eluting at $15.1 \mathrm{~min}$, and $552[\mathrm{M}-40]^{-}$eluting at 16.2 min, respectively (Figures 1 and 2). The major ion for HpDA, monoacetyl-HpDA, and diacetyl-HpDA in the IS mixture was $m / z 462$ [M-60]- eluting at $15.6 \mathrm{~min}, 524$ [M-40] eluting at $16.6 \mathrm{~min}$, and 566 [M-40]- eluting at $17.7 \mathrm{~min}$, respectively. The mass spectra for each corresponding standard peak reflected successive losses of hydrogen $(\mathrm{H})$ and fluorine (F) atoms from derivatized parent amines (HDA $=508$, monoacetyl-HDA $=550$, diacetyl$\mathrm{HDA}=592 \mathrm{~g} / \mathrm{mol})$ and IS amines $(\mathrm{HpDA}=522$, monoacetyl-HpDA $=564$, diacetyl-HpDA $=606 \mathrm{~g} / \mathrm{mol}$ ). Ion selection used in quantification of each amine was based on the most abundant ion fragment in mass spectra.

\section{Quantification of HDA and acetylated HDA in mixture}

Peaks corresponding to HDA and acetylated HDA, as well as HpDA and acetylated HpDA were integrated. Quantification of HDA and diacetyl-HDA in the standard mixture was performed using a linear calibration graph of peak-area response of HDA to peak-area 
response of HpDA in calibration standards $\left(r^{2}=0.999\right)$ and a graph of peak-area response of diacetyl-HDA to peak-area response of diacetyl-HpDA in calibration standards $\left(r^{2}=0.998\right)$, respectively. The concentration of monoacetyl-HDA was calculated by subtracting the known concentration of HDA and diacetyl-HDA from the total concentration $(5 \mu \mathrm{g} / \mathrm{ml})$. The standard mixture yielded $0.09 \mu \mathrm{g} / \mathrm{ml}$ HDA (1.8\%), $2.11 \mu \mathrm{g} / \mathrm{ml}$ monoacetyl-HDA (55.7\%), and $2.80 \mu \mathrm{g} / \mathrm{ml}$ diacetyl-HDA (42.5\%).

\section{Blood biomarker and exposure measurements}

Fifteen spray painters (4 from North Carolina and 11 from Washington State) were randomly selected from our HDI study population (Flack et al. 2010a). Blood samples were collected during each sampling visit when workers consented $(N=35)$. Six workers were sampled twice and eight workers were sampled three times. Blood was collected in EDTA and heparin tubes at the end of the workday and plasma separated within $48 \mathrm{~h}$ of collection. After the plasma and red blood cells (RBCs) were isolated, samples were stored at $-35^{\circ} \mathrm{C}$ until analyzed. Analyses for plasma HDA in acid-hydrolyzed samples have been published elsewhere (Flack et al. 2010a). Briefly, $1 \mathrm{ml}$ of plasma (in duplicate), containing $100 \mu \mathrm{l}$ sulfuric acid and $\mathrm{HpDA}$ IS, was baked at $100^{\circ} \mathrm{C}$ for $16 \mathrm{~h}$. HDA was extracted three times into $2 \mathrm{ml}$ toluene, pooled extracts derivatized with $20 \mu \mathrm{HFBA}$ at $55^{\circ} \mathrm{C}$ for $1 \mathrm{~h}$, and dried under nitrogen. Samples were reconstituted into $60 \mu$ ethyl acetate and analyzed by GC-MS.

Breathing-zone and dermal exposure measurements among these occupationally exposed spray painters have been published elsewhere (Fent et al. 2009a, 2009b). Briefly, a personal air sample in the worker's breathingzone was collected during each spray painting operation of HDI-containing paint. HDI on the skin was collected using three consecutive tape-strips $\left(10 \mathrm{~cm}^{2}\right)$ applied to six different sites on the worker's body (e.g., right and left forearms, hands, and neck) after each paint task. Air and skin samples were analyzed by LC-MS as previously described by Fent and colleagues (2009a, 2009b). Work diaries and questionnaires about workers' physical characteristics (e.g., age, height, weight), PPE use (e.g., coveralls, respirator, gloves), and work environment (e.g., paint booth type, duration of paint tasks) were completed during each visit.

\section{Work-up procedure for $\mathrm{Hb}$ adducts}

The sample work-up procedure was adapted from a previously published method describing the analysis of $\mathrm{Hb}$ adducts of MDA and monoacetylated MDA (Sepai et al. 1995). The separated $\mathrm{RBCs}(4 \mathrm{ml})$ were removed from $-35^{\circ} \mathrm{C}$ storage and kept at room temperature until thawed ( $\sim 30 \mathrm{~min})$. The $\mathrm{Hb}$ was precipitated from the lysate with $20 \mathrm{ml}$ ethanol and centrifuged $(4000 \mathrm{~g}, 10 \mathrm{~min})$. The precipitate was washed with a series of organic solvents (20 ml each of 1:1 ethanol:water, ethanol, 4:1 diethyl ether:ethanol, and diethyl ether), with centrifuging between each wash. The $\mathrm{Hb}$ was dried in a dessicator at $4^{\circ} \mathrm{C}$ overnight.

Portions (200 mg) of $\mathrm{Hb}$ were dissolved in $4 \mathrm{ml}$ sodium hydroxide $(0.1 \mathrm{M})$ in the presence of IS mixture (final concentration $5 \mathrm{ng} / \mathrm{g} \mathrm{Hb}$ ). After $60 \mathrm{~min}$ at room temperature, the amines were extracted (2x) from basic solution into $4 \mathrm{ml}$ dichloromethane, vortexed for $2 \mathrm{~min}$, and then centrifuged for $10 \mathrm{~min}$ at $1000 \mathrm{~g}$. To achieve optimal separation, samples were frozen at $-35^{\circ} \mathrm{C}$ and then allowed to thaw at room temperature. The pooled extracts were dried over 
sodium sulfate and derivatized with $10 \mu \mathrm{HFBA}$. After $60 \mathrm{~min}$ at room temperature, the samples were dried under nitrogen using a TurboVap® LV Evaporator (Zymark Center; Hopkinton, MA). The dried residues were dissolved in $200 \mu \mathrm{l}$ ethyl acetate and placed in an ultrasonic bath for several minutes. The sample solutions were transferred to GC vial inserts and evaporated to dryness using a SpeedVac ${ }^{\circledR}$ (Savant Instruments Inc., Holbrook, NY). The dried residues were dissolved in $60 \mu \mathrm{l}$ ethyl acetate. One reagent blank and two calibration standards were prepared with every set of $\mathrm{Hb}$ samples collected from the workers. The samples were analyzed by GC-MS as described above.

\section{Standard curve preparation for $\mathrm{Hb}$ adduct analysis}

A $50 \mathrm{mg} / \mathrm{ml}$ solution of $\mathrm{Hb}$ was prepared in $0.1 \mathrm{M}$ sodium hydroxide (100 $\mathrm{ml}$ total volume). Portions ( $4 \mathrm{ml}$, in duplicate) of $\mathrm{Hb}$ solution were spiked with HDA and acetylated HDA mixture to make concentration range ( $N=7$, in duplicate): HDA (0-0.045 ng/mg $\mathrm{Hb}$ ), monoacetyl-HDA (0-1.05 ng/mg Hb), and diacetyl-HDA (0-1.40 ng/mg Hb). Each sample was spiked with IS mixture (final concentration $5 \mathrm{pg} / \mathrm{mg} \mathrm{Hb}$ ). Each calibration sample was treated according to procedure for $\mathrm{Hb}$ adduct analysis. Samples were analyzed by GC-MS according to the above procedure. The limit of detection (LOD) for HDA, monoacetylHDA, and diacetyl-HDA was $1.2,0.03$, and $0.05 \mathrm{ng} / \mathrm{g} \mathrm{Hb}$, respectively, as determined using the average of six peak areas with a signal-to-noise ratio $\geq 3$.

\section{Variable construction}

The breathing-zone concentration (BZC) of HDI monomer for each paint task $\left(\mu \mathrm{g} / \mathrm{m}^{3}\right)$ was multiplied by the total paint time ( $\mathrm{min}$ ) for each task and summed together to obtain a daily air exposure level $\left(\mu \mathrm{g} / \mathrm{m}^{3} \times \mathrm{min}\right)$. To obtain a daily inhalation exposure level $\left(\mu \mathrm{g} / \mathrm{m}^{3} \times \mathrm{min}\right)$, the BZC was divided by the assigned protection factor (APF) based on respirator type (OSHA, 2006): none, $\mathrm{APF}=1$; air purifying (half face), $\mathrm{APF}=10$; air purifying (full facepiece), APF = 50; supplied air (full facepiece or hood), APF = 1000; PAPR (full facepiece or hood), APF $=1000$. The dermal concentration from tape-strips $\left(\mathrm{ng} / \mathrm{mm}^{3}\right)$ were summed together for each task, and the task-based dermal values were summed together to obtain a daily dermal exposure level $\left(\mathrm{ng} / \mathrm{mm}^{3}\right.$ ). The concentrations of $\mathrm{Hb}$ adducts ( $\mathrm{ng} / \mathrm{g} \mathrm{Hb}$ ) and plasma HDA $(\mathrm{ng} / \mathrm{ml})$ were used in the data analysis.

\section{Statistical analysis}

The percent coefficient of variation (CV) was calculated for $\mathrm{Hb}$ adduct analysis among replicate samples. The correlation between $\mathrm{Hb}$ adducts and plasma HDA and between $\mathrm{Hb}$ adducts and HDI air or dermal exposure was investigated using linear regression analysis (PROC REG procedure in SAS, version 9.1; SAS Institute, Cary, NC), with a significance level of 0.10 . For regression and summary statistics, all variables were natural logtransformed to meet the assumption of normality (Shapiro-Wilk $W>0.80$ ). Values of LOD/ $\sqrt{2}$ were assigned to all biomarker or exposure samples below the LOD.

Because plasma albumin has a circulating serum half-life of 19 days and $\mathrm{Hb}$ has a lifespan of 120 days, we selected a biologically relevant time frame of 0-4 months of prior HDI exposure to investigate the associations between biomarker and cumulative HDI exposure. The end of the 4-month time frame would correspond to excretion of approximately $98 \%$ 
HDA-albumin adducts and 100\% HDA-Hb adducts resulting from a single exposure to HDI. These cumulative exposure estimates were obtained by summing the daily HDI air or dermal concentrations across all repeated sampling visits for each worker. We investigated the associations between cumulative HDI exposure and blood HDA biomarkers among workers sampled on two or three repeated visits.

\section{Results}

The range of HDA-Hb adduct levels among NC workers $(n=4)$ was $1.3-6.6 \mathrm{ng} / \mathrm{g} \mathrm{Hb}$ and among WA workers $(n=11)$ was $<1.2-37 \mathrm{ng} / \mathrm{g} \mathrm{Hb}$. The majority of samples were above the LOD (95\%) for HDA-Hb concentration. Monoacetyl-HDA-Hb was detected in one worker $(0.06 \mathrm{ng} / \mathrm{g} \mathrm{Hb})$. The $\mathrm{CV}$ among replicate $\mathrm{Hb}$ samples was in the range of $1-20 \%$, which is similar to those reported for plasma HDA, whereas spiked standards were in the range of $1-$ $10 \%$. The lower quantitative precision among $\mathrm{Hb}$ samples compared with spiked standards may be attributed to the release of amines from biological matrices affecting the variation in recovered amines from $\mathrm{Hb}$ conjugates.

The range of HDA in base-treated $\mathrm{Hb}(N=35)$ was $\unlhd .2-37$, and in acid-treated plasma ( $N=$ 35) was $₫ 0.02-0.71 \mathrm{ng} / \mathrm{ml}$ (Table 1). The majority of plasma samples (90\%) were $\boldsymbol{\Perp}_{\mathrm{LOD}}$ for HDA. Figure 3 summarizes the average and the standard deviation for HDA-Hb adduct and plasma HDA levels for each worker, arranged by increasing HDA-Hb level. The plot depicts large within-worker variability in the biomarker levels and a weak association between these biomarkers. The within-worker variability (>90\%) comprised a greater portion of the total variability in both HDA-Hb adduct and plasma HDA level. All BZCs were $\mathbb{L} \mathrm{OD}$ whereas $40 \%$ of dermal exposure concentrations by paint task were $\mathbb{L} \mathrm{OD}$. The HDI monomer dermal exposure range was $2.0-38,100 \mathrm{ng} / \mathrm{mm}^{3}$; the HDI inhalation exposure range was $0.034-864 \mu \mathrm{g} / \mathrm{m}^{3} \times \mathrm{min}$, and the HDI air exposure range was $0.25-2570 \mu \mathrm{g} / \mathrm{m}^{3} \times$ $\min (N=35$; Table 1$)$.

Table 2 summarizes the regression analysis of HDA-Hb adducts or HDA levels in acidtreated plasma versus same day or cumulative HDI dermal, inhalation, or air exposure. The positive association between HDA-Hb adduct concentration and HDI exposure was strongest with cumulative dermal $\left(N=12, r^{2}=0.32, p=0.058\right)$, cumulative inhalation $(N=$ $\left.12, r^{2}=0.35, p=0.042\right)$, or cumulative air exposure $\left(N=12, r^{2}=0.34, p=0.048\right)$. The association between plasma HDA concentration and HDI exposure was strongest with cumulative inhalation $\left(N=12, r^{2}=0.32, p=0.023\right)$ or cumulative air exposure $\left(N=12, r^{2}=\right.$ $0.37, p=0.036$ ). Similar trends were previously reported for plasma HDA in the entire study population $(n=46)$ in which stronger associations were observed with past HDI exposure levels (Flack et al. 2010a). These different time-dependent associations (i.e., same day or cumulative) between HDI air or dermal exposure and plasma HDA or HDA-Hb concentration may be attributed to the half-life of albumin (19 days) and Hb lifespan (120 days), respectively. 


\section{Discussion}

We developed a method to measure HDA-Hb and monoacetyl-HDA-Hb adducts as biomarkers of HDI exposure using mild, alkaline treatment. Because monoacetyl-HDA-Hb was only detected in one worker, further statistical investigation of these compounds was not feasible. Additionally, the formation of diacetyl-HDA-Hb adducts would not be anticipated based on the proposed metabolism of HDI (Flack et al. 2010b). However, the methods described may be adapted to measure urinary diacetyl-HDA in future studies. Using linear regression, we were able to demonstrate the utility of HDA-Hb adduct as a biomarker of cumulative HDI dermal or inhalation exposure. The detection of HDA-Hb adducts in the majority of blood samples indicates that HDA-Hb adducts are sufficiently sensitive and specific as biomarker of cumulative exposure to HDI.

Deacetylation of acetylated amines in the presence of excess anhydride has been claimed to be a critical issue during sample derivatization (Bailey et al. 1990, Schütze et al. 1995). Although the extent of deacetylation was not determined in this study, the addition of $24 \mu \mathrm{g}$ 4-methylaniline to spiked calibration samples prior to derivatization, in order to prevent deacetylation (Schütze et al. 1995, Sepai et al. 1995), did not alter the relative yields of HDA, monoacetyl-HDA, and diacetyl-HDA. Implementing additional steps in the sample work-up method to avoid excess reagent (e.g., drying samples, limiting amount of reagent used) would prevent deacetylation of acetylated amines (Joppich-Kuhn et al. 1997). Therefore, deacetylation of monoacetyl-HDA was not expected to be significant in this study.

We observed $\sim 10$-fold higher total circulating amounts of HDA-Hb adducts (GM $=2.5 \mu \mathrm{g}$, $\mathrm{GSD}=2.1)$ relative to $\mathrm{HDA}$ in acid-treated plasma $(\mathrm{GM}=0.21 \mu \mathrm{g}, \mathrm{GSD}=2.9)$, after adjusting for plasma volume or blood volume (Svirbely \& Iyengar, 1997) and using an average male $\mathrm{Hb}$ concentration $(16 \mathrm{~g} / \mathrm{dl})$. This relative abundance of different blood HDA biomarkers is contrary to that found for other diamine biomarkers (e.g., plasma MDA > MDA-Hb adducts) (Sepai et al. 1995). This may be related to differences in exposure route, the stability of metabolic intermediates, or the differences in the chemical nature of the protein-HDA bonds between aromatic and aliphatic amines, which could influence the yields of various protein adducts (albumin vs. $\mathrm{Hb}$ ). The bis-dithiocarbamate intermediate of $\mathrm{HDI}$, which can be easily transported into RBCs, is more stable compared to toluene diisocyanate or MDI (Chipinda et al. 2006). Therefore, the stability of this metabolic intermediate would allow greater opportunity for cellular uptake and subsequent $\mathrm{Hb}$ adduct formation following further transformation. Another interesting point to consider is the involvement of different enzyme systems in the metabolism of primary aliphatic amines (e.g., HDA, monoacetyl-HDA) versus primary aromatic amines (e.g., MDA), which may be oxidized primarily by cytochrome P450 (Guengerich \& Shimada, 1991). The possible involvement of FMO enzyme system, which participates in oxidation of basic aliphatic amines (Beedham, 1997), in HDA metabolism may explain these differences in the types and yields of various plasma and $\mathrm{Hb}$ adducts. Further research is needed to investigate the chemical nature of these HDA-Hb bonds to better understand how these adducts are formed and their role in disease development. 
Whether oligomers of HDI may be transformed to HDA through metabolic processes or sample treatment (i.e., base or acid treatment) requires further investigation. Liu et al (2004) demonstrated a stronger association between urinary HDA and HDI monomer air levels compared to oligomers suggesting that HDA may be more indicative of monomer than oligomer exposure. Knowledge on oligomer metabolism and their association with external exposures is lacking, thus making HDA the only valid biomarker for HDI monomer exposure. At present, investigation of biomarkers related to HDI oligomer exposure is hindered by the lack of analytical standards and available methods to quantify them. Given that HDI products used in autobody shops contain larger quantities of HDI oligomers compared to monomer, future research is needed to investigate alternative biomarkers that would indicate exposure to these compounds.

The weak association between HDA in acid-treated plasma and HDA-Hb concentration within the same blood sample may indicate varying elimination kinetics among blood biomarkers. Because albumin has a half-life of 19 days, HDA-albumin adducts may be broken down and eliminated by similar elimination kinetics. However, $\mathrm{Hb}$ has a lifespan of 120 days and excretion of HDA-Hb adducts could occur after a longer time frame. Thus, the various long-term elimination kinetics of these metabolites (HDA-Hb adducts and plasma HDA) may have important implications in HDI exposure monitoring and biological availability of these adducts for disease development.

The varying time-dependent associations between HDA in acid-treated plasma or HDA-Hb adducts and HDI dermal, inhalation, or air exposure indicated the utilization of plasma HDA and HDA-Hb adducts as biomarkers of cumulative HDI exposure. The benefit of HDA-Hb adduct analyses is obtaining measures of specific biomarkers that may be related to different exposure routes and metabolic pathways contributing to disease development. Protein adducts may be formed via enzymatic-directed pathways, such as conjugation of metabolites to cysteine residues of glutathione by GST or oxidation of HDA or monoacetyl-HDA by FMO. Polymorphisms in GST have been suggested to play an important role in the inception of ill effects related to diisocyanate exposure (Piirilä et al. 2001). Therefore, individual differences in how diisocyanates are metabolized and the types of products formed may be important factors related to individual susceptibility for disease.

There were several limitations in our estimates of HDI exposure through the inhalation route. All 15 workers wore a respirator during spray painting ( $83 \%$ wore half-face air purifying, $8 \%$ wore full-face air purifying, and $8 \%$ wore supplied air) which would reduce exposure through the inhalation route. However, inhalation exposure may occur due to improper fit and maintenance of respirators, particularly among workers wearing airpurifying respirators, and would contribute to the within- and between-worker variability in biomarker levels. Because breathing-zone measures were taken outside of the respirator, we were unable to adjust for these various factors in our HDI inhalation exposure estimations. Therefore, by adjusting the APF in estimating inhalation exposure may underestimate the workers' true exposure if these issues were a concern. Despite these limitations in estimating inhalation exposure, the associations between blood biomarker concentrations and inhalation exposure estimates were slightly stronger than the associations with air exposure estimates 
indicating that adjusting for respirator use may better reflect exposure through the inhalation route.

There were also several limitations in our estimates of HDI exposure through the dermal route. The high percentage of non-detectable dermal exposure measures ( $60 \%$ of paint tasks) for HDI monomer using tape-stripping of the skin limited our ability in making strong conclusions about the dermal exposure route. However, several workers did not wear gloves (13\%) or coveralls (27\%) and, thus, dermal exposure was a potential route for uptake of HDI. Analytical methods to measure skin protein adducts from HDI exposure and secondary exposure to HDA, the hydrolysis product of HDI, may result in better estimates of dermal exposure. Additionally, there was a positive association between HDI dermal and inhalation exposure $\left(N=35, r^{2}=0.27, p=0.0015\right)$. Therefore, the issue of high collinearity between these exposure routes prevents drawing strong conclusions about the relative significance of either route on internal dose. Nonetheless, we demonstrated a strong, positive association between cumulative HDI dermal exposure and HDA-Hb adduct concentration, indicating the potential contribution of dermal exposure to internal dose levels. Whether exposure route (i.e., dermal vs. inhalation) or exposure type (HDI vs. HDA) has an impact on the type and yield of protein adducts formed requires further investigation.

Another source of the within-worker variability in plasma HDA or HDA-Hb concentrations may be the aging of PPE (e.g., coveralls, respirator filters) over long periods of use, which would lead to eventual breakthrough of the material. Additionally, differences in exposure route (e.g., dermal vs. inhalation) or exposure type (e.g., HDI vs. HDA) would also contribute to both the within- and between-worker variability. Other sources of the betweenworker variability in biomarker concentrations may be related to genetic polymorphisms affecting enzymes regulating HDI metabolism (e.g., GST, NAT). Future studies should investigate whether differences in exposure route, PPE use, and genetic factors play a role in predicting these biomarker levels. Such information could be used to understand the relative importance of dermal and inhalation exposure, workplace covariates, and genetic factors on susceptibility for developing adverse health effects.

\section{Conclusions}

We presented a method for quantifying HDA and monoacetyl-HDA in Hb from HDIexposed individuals and demonstrated the utility of HDA-Hb adducts as biomarkers of exposure to HDI monomer. The time-dependent (same day versus cumulative) associations between HDI dermal, inhalation, or air exposure and levels of HDA-Hb adducts or HDA in acid-treated plasma demonstrate their potential utilization as biomarkers of cumulative HDI exposure. Monoacetyl-HDA $\mathrm{Hb}$ adducts may have limited use as markers of HDI exposure due to the low levels observed in this study population. We demonstrated that HDA-Hb adducts are sensitive and specific biomarkers of HDI monomer exposure. Further characterization of urine and blood biomarkers resulting from HDI exposure may reveal important metabolic pathways contributing to individual susceptibility for disease. 


\section{Acknowledgments}

This study was approved by the Institutional Review Board in the Office of Human Research Ethics at the University of North Carolina at Chapel Hill and by the Washington State Institutional Review Board (WSIRB) at the Washington State Department of Social and Health Service. We thank the automobile-repair shop workers who volunteered to participate in this study and the Safety and Health Assessment \& Research for Prevention (SHARP) program (Olympia, WA).

\section{Declaration of interest}

This study was supported by grants from the National Institute for Occupational Safety and Health (R01-OH007598 and T42/CCT422952), the National Institute of Environmental Health Sciences (P30ES10126), and American Chemistry Council (RSK0015-01).

\section{References}

Aalto-Korte K, Pesonen M, Kuuliala O, Alanko K, Jolanki R. Contact allergy to aliphatic polyisocyanates based on hexamethylene-1,6-diisocyanate (HDI). Contact Derm. 2010; 63:357363. [PubMed: 21070224]

Bailey E, Brooks AG, Bird I, Farmer PB, Street B. Monitoring exposure to 4,4'-methylenedianiline by the gas chromatographymass spectrometry determination of adducts to hemoglobin. Anal Biochem. 1990; 190:175-181. [PubMed: 2291463]

Beedham C. The role of non-P450 enzymes in drug oxidation. Pharm World Sci. 1997; 19:255-263. [PubMed: 9443166]

Berode M, Testa B, Savolainen H. Bicarbonate-catalyzed hydrolysis of hexamethylene diisocyanate to 1,6-diaminohexane. Toxicol Lett. 1991; 56:173-178. [PubMed: 2017775]

Brorson T, Skarping G, Sandström JF, Stenberg M. Biological monitoring of isocyanates and related amines. I. Determination of 1,6-hexamethylene diamine (HDA) in hydrolysed human urine after oral administration of HDA. Int Arch Occup Environ Health. 1990a; 62:79-84. [PubMed: 2295527]

Brorson T, Skarping G, Nielsen J. Biological monitoring of isocyanates and related amines. II. Test chamber exposure of humans to 1,6-hexamethylene diisocyanate (HDI). Int Arch Occup Environ Health. 1990b; 62:385-389. [PubMed: 2228259]

Chipinda I, Stetson SJ, Depree GJ, Simoyi RH, Siegel PD. Kinetics and mechanistic studies of the hydrolysis of diisocyanate-derived bis-thiocarbamates of cysteine methyl ester. Chem Res Toxicol. 2006; 19:341-350. [PubMed: 16544937]

Cockcroft DW, Mink JT. Isocyanate-induced asthma in an automobile spray painter. Can Med Assoc J. 1979; 121:602-604. [PubMed: 497952]

Fent KW, Gaines LG, Thomasen JM, Flack SL, Ding K, Herring AH, Whittaker SG, Nylander-French LA. Quantification and statistical modeling — part I: breathing-zone concentrations of monomeric and polymeric 1,6-hexamethylene diisocyanate. Ann Occup Hyg. 2009a; 53:677-689. [PubMed: 19622637]

Fent KW, Trelles Gaines LG, Thomasen JM, Flack SL, Ding K, Herring AH, Whittaker SG, NylanderFrench LA. Quantification and statistical modeling-part II: dermal concentrations of monomeric and polymeric 1,6-hexamethylene diisocyanate. Ann Occup Hyg. 2009b; 53:691-702. [PubMed: 19635734]

Flack SL, Fent KW, Trelles Gaines LG, Thomasen JM, Whittaker S, Ball LM, Nylander-French LA. Quantitative plasma biomarker analysis in HDI exposure assessment. Ann Occup Hyg. 2010a; 54:41-54. [PubMed: 19805392]

Flack SL, Ball LM, Nylander-French LA. Occupational exposure to HDI: progress and challenges in biomarker analysis. J Chromatogr B Analyt Technol Biomed Life Sci. 2010b; 878:2635-2642.

Gaines LG, Fent KW, Flack SL, Thomasen JM, Ball LM, Richardson DB, Ding K, Whittaker SG, Nylander-French LA. Urine 1,6-hexamethylene diamine (HDA) levels among workers exposed to 1,6-hexamethylene diisocyanate (HDI). Ann Occup Hyg. 2010; 54:678-691. [PubMed: 20530123]

Gorrod JW. Differentiation of various types of biological oxidation of nitrogen in organic compounds. Chem Biol Interact. 1973; 289:289-303. [PubMed: 4604326] 
Guengerich FP, Shimada T. Oxidation of toxic and carcinogenic chemicals by human cytochrome P-450 enzymes. Chem Res Toxicol. 1991; 4:391-407. [PubMed: 1912325]

Herrick CA, Xu L, Wisnewski AV, Das J, Redlich CA, Bottomly K. A novel mouse model of diisocyanate-induced asthma showing allergic-type inflammation in the lung after inhaled antigen challenge. J Allergy Clin Immunol. 2002; 109:873-878. [PubMed: 11994714]

Janko M, McCarthy K, Fajer M, van Raalte J. Occupational exposure to 1,6-hexamethylene diisocyanate-based polyisocyanates in the state of Oregon, 1980-1990. Am Ind Hyg Assoc J. 1992; 53:331-338. [PubMed: 1609744]

Joppich-Kuhn R, Hänggi R, Sagelsdorff P, Smith AE, Weideli HJ, Joppich M. Determination of dichlorobenzidine-hemoglobin adducts by GC/MS-NCI. Int Arch Occup Environ Health. 1997; 69:240-246. [PubMed: 9137997]

Landaw, SA. Homeostasis, survival, and red cell kinetics: measurement and imaging of red blood cell production. In: Hoffman, R.; E Benz, E.; Shattil, SJ.; Furie, B.; Cohen, HJ., editors. Hematology: Basic Principles and Practice. New York: Churchill Livingstone; 1991. p. 274-290.

Lesage J, Goyer N, Desjardins F, Vincent JY, Perrault G. Workers' exposure to isocyanates. Am Ind Hyg Assoc J. 1992; 53:146-153. [PubMed: 1543131]

Lind P, Dalene M, Lindström V, Grubb A, Skarping G. Albumin adducts in plasma from workers exposed to toluene diisocyanate. Analyst. 1997; 122:151-154. [PubMed: 9124697]

Liu Y, Berode M, Stowe MH, Holm CT, Walsh FX, Slade MD, Boeniger MF, Redlich CA. Urinary hexane diamine to assess respiratory exposure to hexamethylene diisocyanate aerosol: a human inhalation study. Int J Occup Environ Health. 2004; 10:262-271. [PubMed: 15473079]

Maître A, Berode M, Perdrix A, Stoklov M, Mallion JM, Savolainen H. Urinary hexane diamine as an indicator of occupational exposure to hexamethylene diisocyanate. Int Arch Occup Environ Health. 1996; 69:65-68. [PubMed: 9017437]

OSHA. Respiratory protection - 1910.134, Regulation (Standards- 29 CFR). U.S. Department of Labor; http://www.osha.gov/ [Accessed 24 January 2011]

Pauluhn J, Lewalter J. Analysis of markers of exposure to polymeric methylene-diphenyl diisocyanate (pMDI) in rats: a comparison of dermal and inhalation routes of exposure. Exp Toxicol Pathol. 2002; 54:135-146. [PubMed: 12211634]

Peters, TJ. Serum albumin. In: Putnam, FW., editor. The Plasma Proteins: Structure, Function, and Genetic Control. New York: Academic Press; 1975. p. 133-181.

Piirilä P, Wikman H, Luukkonen R, Kääriä K, Rosenberg C, Nordman H, Norppa H, Vainio H, Hirvonen A. Glutathione S-transferase genotypes and allergic responses to diisocyanate exposure. Pharmacogenetics. 2001; 11:437-445. [PubMed: 11470996]

Pronk A, Preller L, Raulf-Heimsoth M, Jonkers IC, Lammers JW, Wouters IM, Doekes G, Wisnewski AV, Heederik D. Respiratory symptoms, sensitization, and exposure response relationships in spray painters exposed to isocyanates. Am J Respir Crit Care Med. 2007; 176:1090-1097. [PubMed: 17656675]

Pronk A, Yu F, Vlaanderen J, Tielemans E, Preller L, Bobeldijk I, Deddens JA, Latza U, Baur X, Heederik D. Dermal, inhalation, and internal exposure to 1,6-HDI and its oligomers in car body repair shop workers and industrial spray painters. Occup Environ Med. 2006; 63:624-631. [PubMed: 16728504]

Redlich CA, Karol MH, Graham C, Homer RJ, Holm CT, Wirth JA, Cullen MR. Airway isocyanateadducts in asthma induced by exposure to hexamethylene diisocyanate. Scand J Work Environ Health. 1997; 23:227-231. [PubMed: 9243734]

Rosenberg C, Nikkilä K, Henriks-Eckerman ML, Peltonen K, Engströrm K. Biological monitoring of aromatic diisocyanates in workers exposed to thermal degradation products of polyurethanes. $\mathbf{J}$ Environ Monit. 2002; 4:711-716. [PubMed: 12400919]

Schütze D, Sepai O, Lewalter J, Miksche L, Henschler D, Sabbioni G. Biomonitoring of workers exposed to 4,4'-methylenedianiline or 4,4'-methylenediphenyl diisocyanate. Carcinogenesis. 1995; 16:573-582. [PubMed: 7697816]

Sepai O, Henschler D, Sabbioni G. Albumin adducts, hemoglobin adducts and urinary metabolites in workers exposed to 4,4'-methylenediphenyl diisocyanate. Carcinogenesis. 1995; 16:2583-2587. [PubMed: 7586170] 
Sparer J, Stowe MH, Bello D, Liu Y, Gore RJ, Youngs F, Cullen MR, Redlich CA, Woskie SR. Isocyanate exposures in autobody shop work: the SPRAY study. J Occup Environ Hyg. 2004; 1:570-581. [PubMed: 15559329]

Svirbely, JR.; Iyengar, S. The Medical Algorithms Project, Release 24.0. Chapter 2: Body dimensions and blood volumes. Blood volume from height and weight. 1997. Retrieved 2008 August. Available from: http://www.medal.org

Tinnerberg H, Skarping G, Dalene M, Hagmar L. Test chamber exposure of humans to 1,6hexamethylene diisocyanate and isophorone diisocyanate. Int Arch Occup Environ Health. 1995; 67:367-374. [PubMed: 8567087]

Vandenplas O, Cartier A, Lesage J, Cloutier Y, Perreault G, Grammer LC, Shaughnessy MA, Malo JL. Prepolymers of hexamethylene diisocyanate as a cause of occupational asthma. J Allergy Clin Immunol. 1993; 91:850-861. [PubMed: 8473673]

Wikman H, Piirilä P, Rosenberg C, Luukkonen R, Kääriä K, Nordman H, Norppa H, Vainio H, Hirvonen A. N-Acetyltransferase genotypes as modifiers of diisocyanate exposure-associated asthma risk. Pharmacogenetics. 2002; 12:227-233. [PubMed: 11927838]

Williams NR, Jones K, Cocker J. Biological monitoring to assess exposure from use of isocyanates in motor vehicle repair. Occup Environ Med. 1999; 56:598-601. [PubMed: 10615291]

Wisnewski AV, Srivastava R, Herick C, Xu L, Lemus R, Cain H, Magoski NM, Karol MH, Bottomly $\mathrm{K}$, Redlich CA. Identification of human lung and skin proteins conjugated with hexamethylene diisocyanate in vitro and in vivo . Am J Respir Crit Care Med. 2000; 162:2330-2336. [PubMed: 11112159]

Zissu D, Binet S, Limasset JC. Cutaneous sensitization to some polyisocyanate prepolymers in guinea pigs. Contact Derm. 1998; 39:248-251. [PubMed: 9840262] 


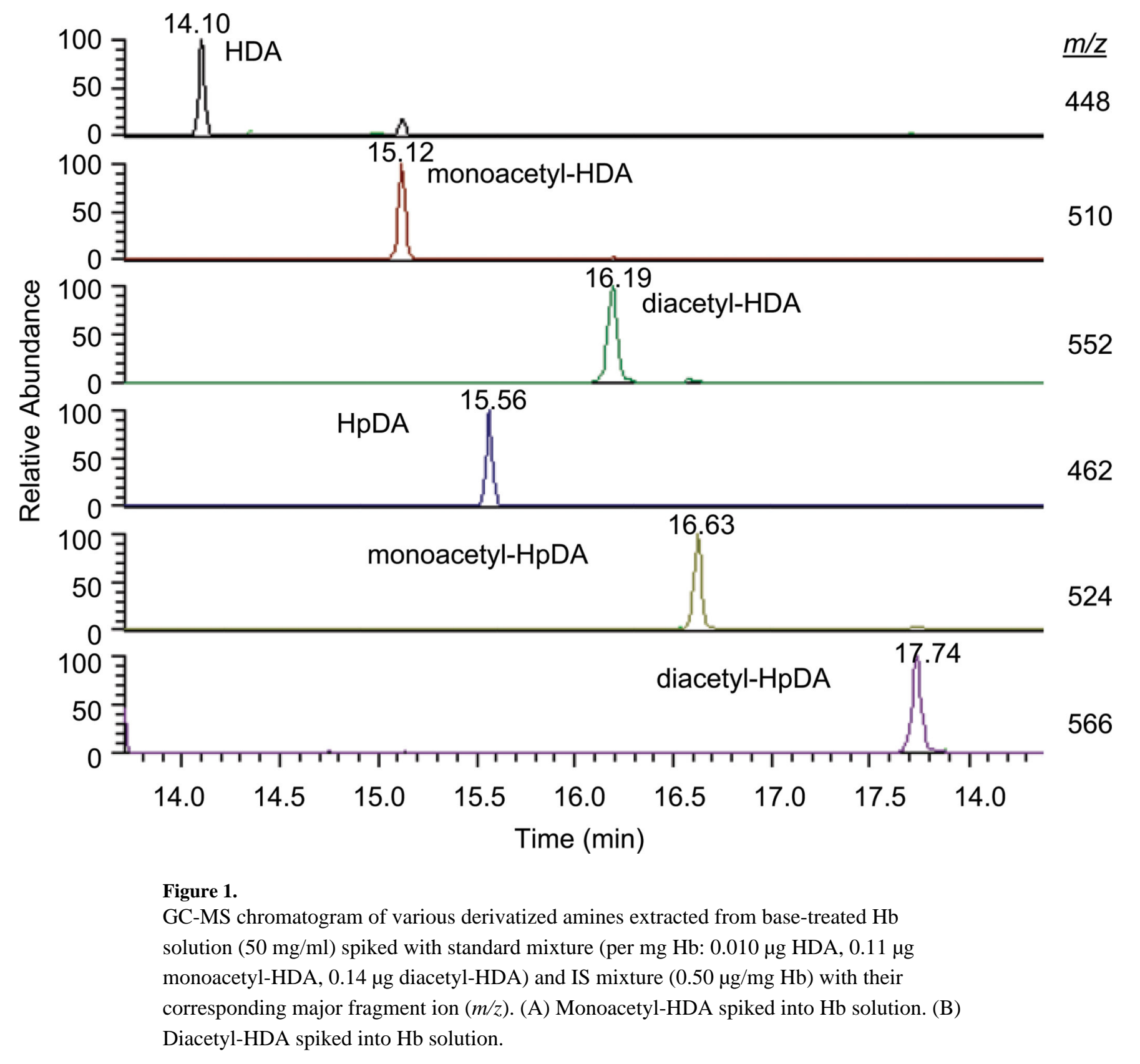



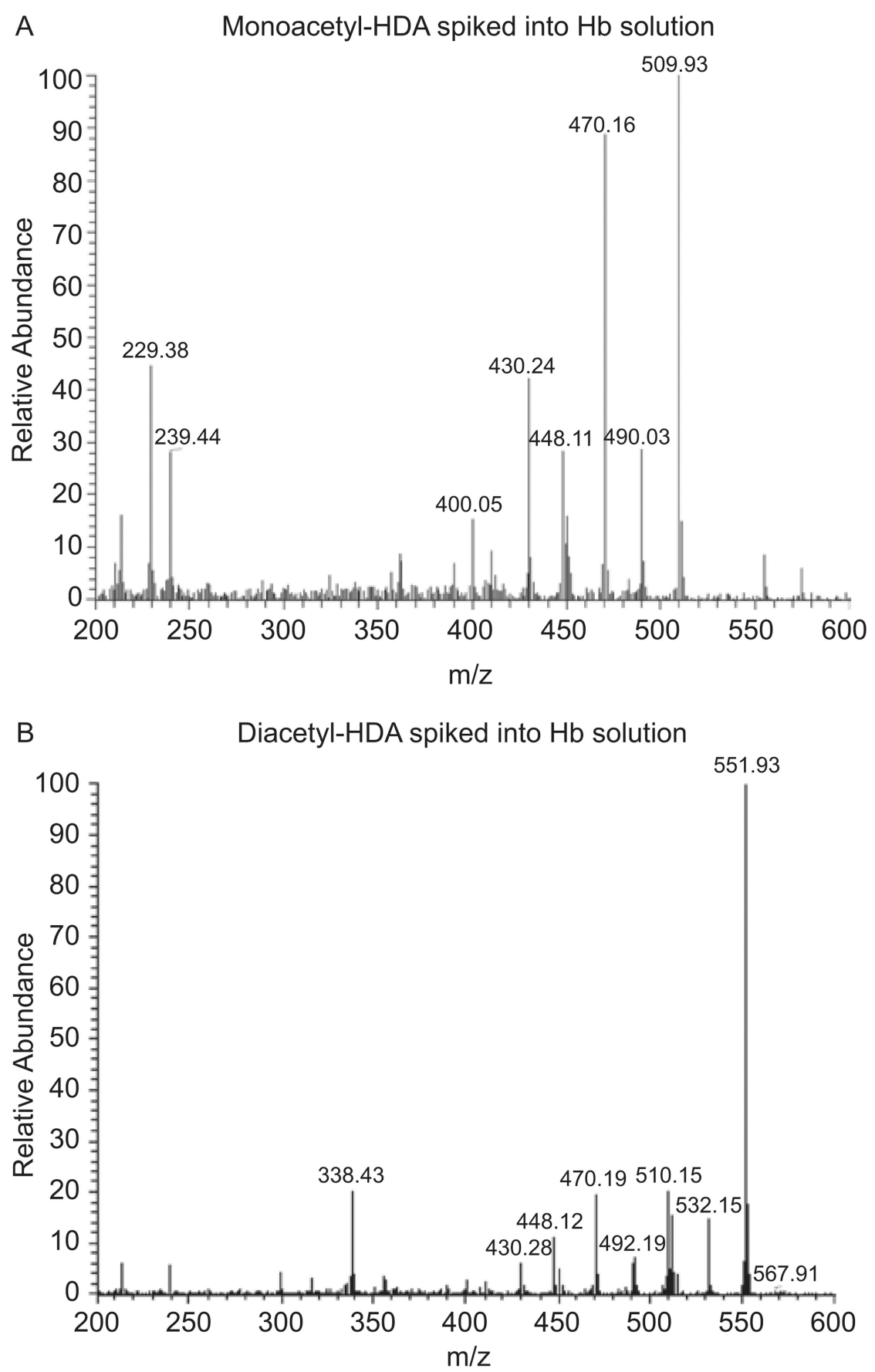

Figure 2.

GC mass spectra using negative ion chemical ionization mode $(\mathrm{m} / \mathrm{z} 200-600)$ of (A) derivatized monoacetyl-HDA $(0.11 \mu \mathrm{g} / \mathrm{mg} \mathrm{Hb})$ and (B) diacetyl-HDA $(0.14 \mu \mathrm{g} / \mathrm{mg} \mathrm{Hb})$ extracted from base-treated $\mathrm{Hb}$ solution $(50 \mathrm{mg} / \mathrm{ml})$ and spiked with standard mixture. 


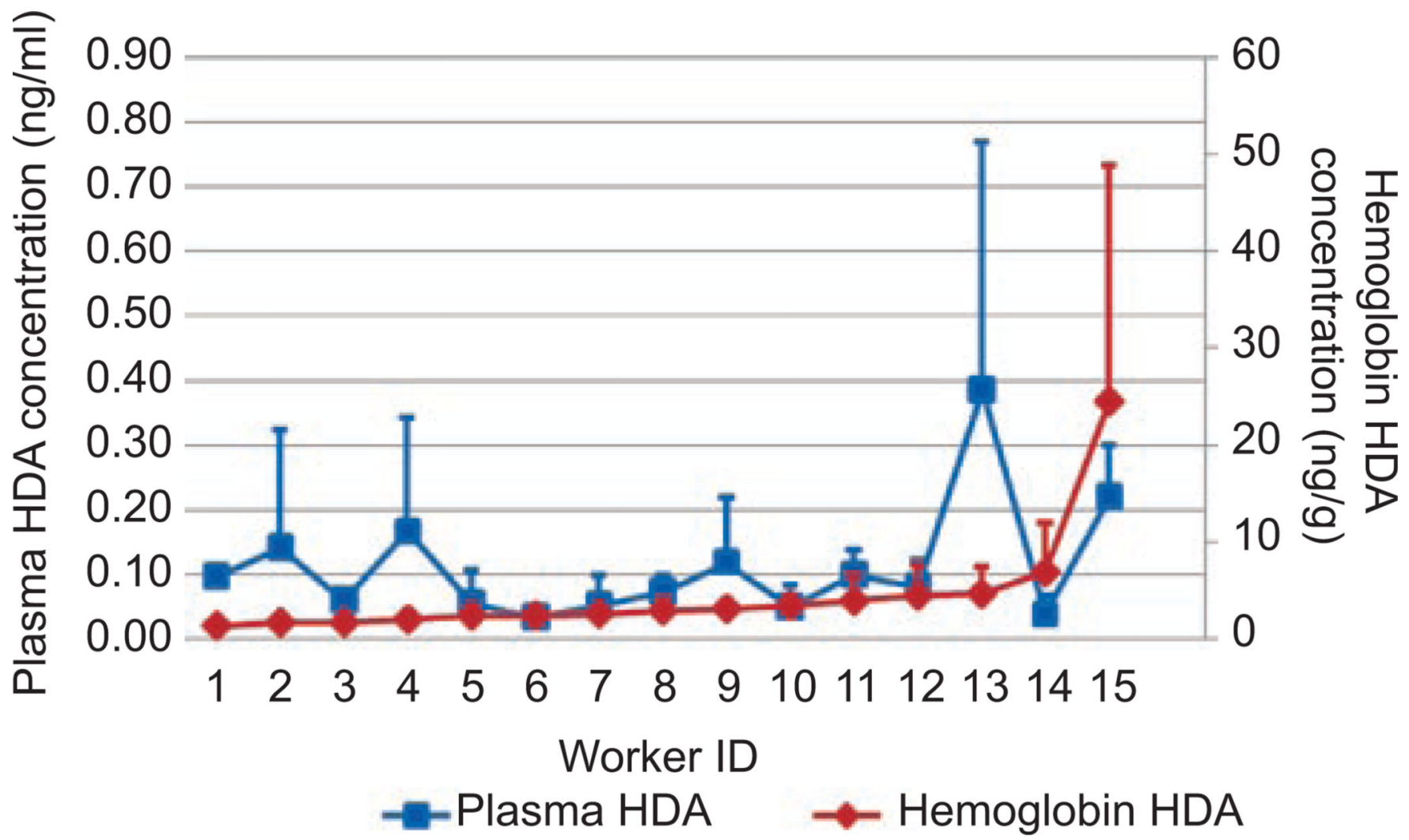

Figure 3.

Average values and standard deviations of HDA-Hb adduct (ng/g) and plasma HDA (ng/ml) concentrations in each worker across sampling visits $(n=15)$ and arranged by increasing HDA-Hb concentration. 


\section{Table 1}

Summary of the measured HDA-Hb adduct (ng/g Hb), HDA in acid-treated plasma (ng/ml), HDI dermal $\left(\mathrm{ng} / \mathrm{mm}^{3}\right)^{a}$, HDI inhalation $\left(\mu \mathrm{g} / \mathrm{m}^{3} \times \mathrm{min}\right)^{b}$, and HDI air $\left(\mu \mathrm{g} / \mathrm{m}^{3} \times \mathrm{min}\right)^{c}$ exposure levels among 15 automotive spray painters.

\begin{tabular}{lcccc}
\hline Sample & $\boldsymbol{N}$ & GM & GSD & Range \\
\hline HDA-Hb & 35 & 3.0 & 2.0 & $1.3-37$ \\
Plasma HAD & 35 & 0.061 & 2.7 & $0.012-0.71$ \\
HDI dermal exposure $^{a}$ & 72 & 131 & 7.1 & $2.0-38,100$ \\
HDI inhalation exposure $^{b}$ & 72 & 7.8 & 11 & $0.034-864$ \\
HDI air exposure $^{c}$ & 72 & 72 & 6.1 & $0.25-2570$ \\
\hline
\end{tabular}

GM, geometric mean; GSD, geometric standard deviation; $N$, number of biological samples or task-based exposure values.

$$
\sum_{j=1}^{n}
$$

$a_{j=1}$ (HDI dermal exposure) $j$, sum of HDI dermal concentration across all daily tasks ( $j$ ) was obtained by calculating the sum of the dermal concentration measured for each task and summing the task-based dermal values.

$\sum_{j=1}^{n}$

$b_{j=1}$ (HDI inhalation exposure) $j$, sum of HDI inhalation concentration across all daily tasks ( $j$ ) was obtained by dividing the measured breathingzone concentration by the OSHA assigned protection factor based on respirator type (OSHA, 2006) for each task, multiplying the adjusted breathing-zone concentration for each paint task $\left(\mu \mathrm{g} / \mathrm{m}^{3}\right)$ by the paint time $(\mathrm{min})$, and summing the task-based inhalation values.

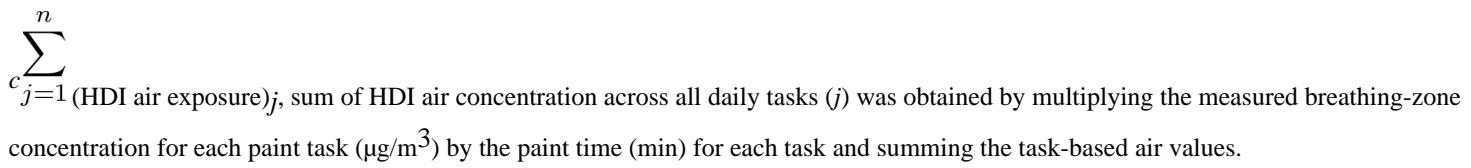




\section{Table 2}

Log-transformed concentration of HDA-Hb adduct (ng/g $\mathrm{Hb}$ ) or HDAs in acid-treated plasma $(\mathrm{ng} / \mathrm{ml})$ on last sampling visit versus the log-transformed same day or cumulative HDI dermal $\left(\mathrm{ng} / \mathrm{mm}^{3}\right)$, inhalation $\left(\mu \mathrm{g} / \mathrm{m}^{3} \times\right.$ $\mathrm{min})$, or air $\left(\mu \mathrm{g} / \mathrm{m}^{3} \times \mathrm{min}\right)$ exposure level among workers sampled two $(n=4)$ or three times $(n=8)$.

\begin{tabular}{|c|c|c|c|c|}
\hline Exposure route & Time of HDI exposure ${ }^{a}$ & Blood HDA & $r^{2}$ & $p$ Value $^{b}$ \\
\hline \multirow[t]{4}{*}{ Dermal } & Same day & $\mathrm{Hb}$ & 0.15 & 0.206 \\
\hline & & Plasma & 0.033 & 0.571 \\
\hline & Cumulative & $\mathrm{Hb}$ & 0.32 & 0.058 \\
\hline & & Plasma & 0.13 & 0.255 \\
\hline \multirow[t]{4}{*}{ Inhalation } & Same day & $\mathrm{Hb}$ & 0.22 & 0.126 \\
\hline & & Plasma & 0.36 & 0.041 \\
\hline & Cumulative & $\mathrm{Hb}$ & 0.35 & 0.042 \\
\hline & & Plasma & 0.42 & 0.023 \\
\hline \multirow[t]{4}{*}{ Air } & Same day & $\mathrm{Hb}$ & 0.18 & 0.173 \\
\hline & & Plasma & 0.20 & 0.150 \\
\hline & Cumulative & $\mathrm{Hb}$ & 0.34 & 0.048 \\
\hline & & Plasma & 0.37 & 0.036 \\
\hline
\end{tabular}

